\title{
Non-invasive prenatal testing: what an obstetrician needs to know
}

\author{
Mishu Mangla* \\ Department of Obstetrics and Gynaecology, Himalayan Institute of Medical Sciences, Jollygrant, Dehradun,
} Uttarakhand, India

Received: 23 September 2020

Accepted: 31 October 2020

*Correspondence:

Dr. Mishu Mangla,

E-mail: mishusingla83@gmail.com

Copyright: ( $\odot$ the author(s), publisher and licensee Medip Academy. This is an open-access article distributed under the terms of the Creative Commons Attribution Non-Commercial License, which permits unrestricted non-commercial use, distribution, and reproduction in any medium, provided the original work is properly cited.

\begin{abstract}
No field in obstetrics has seen such fast advancement, as the field of prenatal screening and diagnosis. A wide variety of tests are available today, and this at times becomes confusing both for the patient and the treating doctor that which screening test would be best suited in the given circumstances. Non-invasive prenatal screening, with its numerous advantages is rapidly becoming the test of first choice, especially in the affording set of population. Although, the test has a very high sensitivity and a very good positive predictive value, this too suffers from some disadvantages which should be clear to the obstetrician ordering the test. A good knowledge about the test, the ideal target population in which this should be offered as the primary screening tool and limitations of the test should be known to all practicing obstetricians and primary health care providers. The current review aims to provide a simplified and updated knowledge regarding non-invasive prenatal testing (NIPT), its major advantages and disadvantages and summarizes the role of ultrasound in patients with negative NIPT.
\end{abstract}

Keywords: Non-invasive prenatal testing, Prenatal screening, Antenatal screening

\section{INTRODUCTION}

Prenatal screening has now become an integral part of antenatal care, as every obstetrician and patient expects that the outcome of each and every pregnancy should be healthy newborn, free from any type of disease or disability. Chromosomal abnormalities have an incidence as high as 1 in 150 births, although it is much higher in early pregnancy as they account for majority of early pregnancy losses. ${ }^{1}$ Autosomal trisomies are most common aneuploidy, and among these Down syndromes is the most common. ${ }^{1}$

Probably, no field in obstetrics has seen such fast advancement, as the field of prenatal screening and diagnosis. Numerous options are available to the obstetrician and it may be confusing at times to decide that which test would be most appropriate in the given circumstances. Conventional screening tests such as dual marker, quadruple test and even ultrasound markers like nuchal translucency suffer from a major disadvantage of low positive predictive value $(<5 \%)$. ${ }^{2,3}$ This means that only about $4-5 \%$ of patients undergoing invasive testing after a positive screening test, actually carry a fetus with aneuploidy. So, a test with a high sensitivity as well as a high positive predictive value, would be very beneficial in avoiding unnecessary invasive testing.

Non-invasive prenatal testing (NIPT) has a sensitivity $>99 \%$ and a positive predictive value $>80 \%$ for Down syndrome in high risk cases. ${ }^{4}$ Although, the sensitivity still remains high, the positive predictive value is not that very good in low risk population. Therefore, a good knowledge about the test, the ideal target population in which this should be offered as the primary screening tool and limitations of the test should be known to all practicing obstetricians and primary health care providers. 


\section{DISCUSSION}

\section{Basis of NIPT- cell free DNA?}

Cell free deoxyribonucleic acid (CfDNA) are small fragments of DNA about 150 to 250 base pairs in size derived by the apoptosis of cytotrophoblast cells of placenta. They were first described by Lo et al in 1997, who discovered them from the $\mathrm{Y}$ chromosome of male fetuses in the plasma of pregnant woman. ${ }^{5}$ CfDNA normally constitutes $3-13 \%$ of total maternal free DNA. ${ }^{6}$ The concentration increases $0.1 \%$ per week till 20 weeks and $1 \%$ per week thereafter. It has a very short half-life of approximately 16 minutes and is eliminated within 2 days of delivery. Therefore, there are no chances that an abnormal result could be due to the effect of carrying an aneuploid fetus in previous pregnancy. CfDNA can be isolated as early as 5 weeks of pregnancy and almost always by 9 weeks, making this test possible from as early as 9 weeks to late pregnancy. ${ }^{7}$

\section{Fetal fraction-how relevant is it?}

Maternal plasma contains circulating cell free DNA fragments, derived both from the mother herself as well as the placenta. The amount contributed by the placenta is called as the fetal fraction. The report of non-invasive prenatal testing is based on the relative contribution of genetic material for a particular chromosome both from the fetus and from the mother. So, fetal fraction, i.e. the proportion of material that is fetal in origin, should be above a particular threshold, for results to be obtained. An adequate fetal fraction is anywhere above $8 \%$. A fetal fraction of less than $4 \%$ is too low for results to be reported. It is extremely difficult to differentiate between the euploid and aneuploid distributions, if the fetal fraction is too low, especially when counting methodologies are used for NIPT. ${ }^{8}$ A very important factor affecting fetal fractions is the maternal weight and body mass index. Fetal fraction is low in obese women, decreasing from an average of $11.7 \%$ at $60 \mathrm{~kg}$ to $3.9 \%$ at $160 \mathrm{~kg} .{ }^{9}$ The active apoptosis and necrosis of adipose tissue leads to a relative increase in the maternal fraction in overweight women, thereby increasing the 'maternal fraction'.

\section{NIPT methodologies}

\section{Massive parallel shotgun sequencing}

After initial amplification, sequencing of maternal and fetal cell free DNA mixture is done and the chromosomal origin of each DNA fragment is obtained, after comparison with the human genome. In an approach referred to as 'counting' a ' $z$ score' is calculated which is the ratio of the number of sequences reads from a specific chromosome of interest to the number of sequences reads from the reference chromosome in the standard human genome. If the $\mathrm{z}$ score for a particular chromosome is above the threshold, sample is labelled as high risk for trisomy for that particular chromosome. ${ }^{10}$
Targeted massive parallel shotgun sequencing or chromosome selective sequencing

In this technique a selective amplification and sequencing of specific genomic regions of interest, for example, focused analysis of chromosomes $13,18,21, \mathrm{X}$, and $\mathrm{Y}$ is done. ${ }^{11}$ The advantage obviously, is lesser cost. This method can also detect triplody and uniparental disomy.

\section{Single nucleotide polymorphism (SNP) based approach}

SNP are normal genetic variations between any two individuals

Applying SNP analysis to the NIPT helps to determine the difference between the DNA of mother and her child and also the variations in copy number. ${ }^{12}$ Multiplex polymerase chain reaction amplification and sequencing of plasma DNA (comprising a mixture of maternal and foetal DNA) and the buffy coat DNA (which contains only maternal DNA) for SNP sequences is done. The Next generation aneuploidy test using SNPs (NATUS) algorithm which is used, further can identify monosomy, uniparental disomy, or trisomy in the fetus. This method is comparatively less dependent on the fetal fraction, minimizes the effect of maternal mosaicism as it differentiates fetal and maternal DNA effectively, and can even detect the possibility of vanishing twin. ${ }^{13}$

\section{Indications}

According to American college of obstetrics and gynaecology, NIPT should be done only in high risk females including; women with age more than 35 years; ultrasound examination suggestive of a possible problem with the fetus; positive first or second trimester screening tests; women who previously had babies with aneuploidy and the lady herself carries a chromosomal problem that puts her at a high risk of having baby with trisomy 21,13 or $18 .{ }^{1}$

Determination of the blood group of the fetus, especially in Rhesus ( $\mathrm{Rh}$ ) negative pregnancy is another important clinical use of NIPT. ${ }^{14}$ This is very important and cost effective as this would definitely cut out on the need of extensive monitoring by doppler that would otherwise be needed to be done in such pregnancies.

Another very important clinical utility is in cases of sexlinked diseases, where early knowledge of the fetal sex could alter the management. ${ }^{15}$ One example is congenital adrenal hyperplasia, which results in overproduction of androgens and thereby virilization of the female fetus. Starting treatment in early pregnancy with steroids is very important to prevent masculinization of female fetus, while this treatment is unnecessary if the fetus is a male.

Cell free DNA can also be used to determine some paternally derived autosomal dominant genetic conditions 
in the fetus like myotonic dystrophy and achondroplasia. ${ }^{16,17}$

In twin pregnancies, it has been proved that NIPT is better than conventional screening methods, for trisomy 21 but same has not been proved for trisomy 13 and $18 .^{18}$

NIPT should not be done if there are clearly evident ultrasound abnormalities in the fetus. ${ }^{19}$ The results are not reliable if the mother has a history of blood transfusion in the last three months, is on immunotherapy, stem cell therapy or there is a history of organ transplantation. ${ }^{20}$

\section{Pre-test counselling}

An extensive pretest counselling is a must before a patient goes for NIPT. The first thing to be clarified is that all genetic testing, although recommended strongly in some cases, is purely optional and may be declined. Cf-DNA is a screening test with a very high sensitivity and specificity, but it is not a diagnostic test. A negative result does not rule out the possibility of having a baby with a chromosomal disorder or other disorders that the cell-free DNA test does not test for. Both false positives and false negative test reports may occur with NIPT, and thus any positive test needs to be confirmed with invasive testing before a definitive action such as pregnancy termination is decided upon. There may even be certain situations in which NIPT may not yield any result at all, i.e. a no call result, which may by itself be an indication of increased risk of aneuploidy and may thus need invasive testing. Further patient needs to be told about the cost of NIPT which is still high. They need to be told clearly that not all chromosomal anomalies can be detected by NIPT.

\section{Factors affecting the results of NIPT}

\section{Gestational age}

Since the fetal fraction is dependent on gestational age, so usually tests done before 10 weeks may be inconclusive, due to a low fetal fraction.

\section{Maternal Obesity}

As maternal weight increases, the fetal fraction decreases, therefore the test is not very useful in overweight mothers. ${ }^{21}$

\section{Confined placental mosaicism}

Although the condition is not very common, but aneuploidy status confined just to the placenta with a normal fetus should be kept in mind.

\section{Maternal malignancy}

This should specially be suspected and patient to be kept on follow up when NIPT results are positive for two or more aneuploidies. ${ }^{22}$

\section{Vanishing twins}

Cell free DNA from the apoptosis of feto-placental unit of vanished or non-viable twin can interfere with the results.

\section{Maternal mosaicism}

An abnormal maternal karyotype i.e. maternal mosaicism is also an important factor leading to fallacious results. ${ }^{23}$

\section{Advantages and disadvantages of NIPT}

NIPT has many advantages over conventional screening tests. Firstly, it is highly sensitive and has very high positive predictive value for common autosomal trisomies like Down syndrome, Edward syndrome and Patau syndrome. Secondly, it is non-invasive and therefore, no risks to the fetus. Thirdly, it gives additional information like blood group of the fetus. It has been calculated that if the referrals for invasive testing were all bases only on the basis of NIPT, approximately $98 \%$ of all procedures could be avoided.

Disadvantages though not major, should be kept in mind before ordering the test. It is not a diagnostic test, so all cases who screen positive on NIPT should be confirmed by invasive testing. Although highly sensitive and specific for Down syndrome, for other aneuploidies may not hold the same value. It is not useful for screening of single gene disorders and structural abnormalities in the fetus. No call result on NIPT, which may be due to a low fetal fraction or even aneuploidy itself, again leaves the obstetrician in the same dilemma or what to do. It does not differentiate fetal from maternal DNA, so a positive test report could actually be due to confined placental mosaicism, maternal malignancy or aneuploidy or even a vanishing twin. Lastly, its high cost is still the major obstacle in its widespread use, especially in developing countries.

\section{No call result on NIPT- why and what next?}

NIPT fails to give any result in approximately $1-3 \%$ of women. Although, the most common reason for such a report is low fetal fraction usually due to high maternal body mass index, other reasons like gestational age less the 9 weeks when the sample was sent should also be kept in mind. Another reason for repeated 'no call results' on NIPT could also be presence of auto immune diseases or maternal ingestion of drugs like heparin and aspirin. ${ }^{24,25}$ Low molecular weight heparin increases the concentration of smaller plasma DNA fragments with higher GC content. This elevated GC content can corelate with increased $\mathrm{z}$ score of chromosomes 18 and decreased z-scores for chromosome 13 and chromosome 21 in NIPT assays. ${ }^{25}$

There have also been recent studies indicating this "no call result" to be a marker of adverse pregnancy outcomes in itself. It was found that women with no call result on NIPT were more prone to develop preeclampsia, gestational diabetes and even at higher risk of carrying fetus with 
chromosomal aneuploidy than their counterparts ${ }^{26}$. Although a redraw of blood sample to repeat NIPT may be an option, but it is usually successful in only about $65-70 \%$ of cases. ${ }^{27}$ Therefore, women with no call result on NIPT may thus be offered invasive testing in the form of chorionic villus sampling, and a thorough counselling regarding preventive measures against preeclampsia and gestational diabetes. ${ }^{26}$

As per the recommendations of American college of medical genetics and genomics, it the obstetrician is fairly sure that the sample for NIPT was drawn at an appropriate gestational age, ang still it shows a low fetal fraction, a repeat draw is not appropriate, invasive testing is a better option.

\section{Is ultrasound still necessary in women with negative NIPT?}

In 2017 ACOG and Society of maternal and fetal medicine (SMFM), issued a joint statement that nuchal translucency measurement for aneuploidy risk is not necessary at the time of cfDNA screening in the first trimester. However, this statement should be interpreted with caution as NT measurement in the first trimester in not just a marker of aneuploidy but also other diseases like congenital heart disease, metabolic defects or even fetal anemia which are not detected by NIPT.

Therefore, the importance of a complete anatomy scan at 11 to 14 weeks cannot be underrated. Further, the detection rate of all chromosomal anomalies was found to be $88.9 \%$, if only CfDNA was used as screening test, which went up to around $95 \%$ if CfDNA and NT were combined. ${ }^{28}$

If a woman already has a report of negative NIPT, in the second trimester target scan echogenic intracardiac focus, choroid plexus cyst, sandal gap and clinodactyly should be reported as normal variants. Pyelectasis, single umbilical artery, echogenic bowel, thick nuchal fold, hypoplastic nasal bone, short femur or humerus and ventriculomegaly should not be reported as soft markers of aneuploidy but their evaluation should be as per routine clinical indications. $^{28}$

\section{CONCLUSION}

NIPT is a very good screening test, but complete knowledge regarding its limitations and drawbacks is a must among all practicing obstetricians and health care providers. A detailed pre-test counselling must be done, so that even the patients also know what and what not to expect from the test, and even undue anxiety in case of 'no call' result is avoided.

\section{Funding: No funding sources}

Conflict of interest: None declared

Ethical approval: Not required

\section{REFERENCES}

1. Committee on Practice Bulletins-Obstetrics, Committee on Genetics, and the Society for MaternalFetal Medicine. ACOG practice bulletin number 163: screening for fetal aneuploidy. Obstet Gynecol. 2016;127:e123-37.

2. Norton ME, Jacobsson B, Swamy GK, Laurent LC, Ranzini AC, Brar H, et al. Cell-free DNA analysis for noninvasive examination of trisomy. N Engl J Med. 2015;372:1589-97.

3. Bianchi DW, Parker RL, Wentworth J, Madankumar R, Saffer C, Das AF, et al. CARE Study Group. DNA sequencing versus standard prenatal aneuploidy screening. N Engl J Med. 2014;370:799-80.

4. Gil MM, Akolekar R, Quezada MS, Bregant B, Nicolaides KH. Analysis of cell-free DNA in maternal blood in screening for aneuploidies: meta-analysis. Fetal Diagn Ther. 2014;35:156-73.

5. Lo YM, Corbetta N, Chamberlain PF, Rai V, Sargent IL, Redman CW, et al. Presence of fetal DNA in maternal plasma and serum. Lancet. 1997;350(9076):485-7.

6. Bischoff FZ, Sinacori MK, Dang DD, Marquez-Do D, Horne C, Lewis DE, et al. Cell-free fetal DNA and intact fetal cells in maternal blood circulation: implications for first and second trimester noninvasive prenatal diagnosis. Hum Reprod Update. 2002;8(6):493-500.

7. Illanes S, Denbow M, Kailasam C, Finning K, Soothill PW. Early detection of cell-free fetal DNA in maternal plasma. Early Hum Dev. 2007;83(9):563-6.

8. Canick JA, Palomaki GE, Kloza EM, LambertMesserlian GM, Haddow JE. The impact of maternal plasma DNA fetal fraction on next generation sequencing tests for common fetal aneuploidies. Prenat Diagn. 2013;33(7):667-74.

9. Ashoor G, Syngelaki A, Poon LC. Fetal fraction in maternal plasma cell-free DNA at 11-13 weeks' gestation: relation to maternal and fetal characteristics. Ultrasound Obstet Gynecol. 2013;41(1):26-32.

10. Pantiukh KS, Chekanov NN, Zaigrin IV, Zotov AM, Mazur AM, Prokhortchouk EB. Report on noninvasive prenatal testing: classical and alternative approaches. F1000Research. 2016;5.

11. Cuckle H, Benn P, Pergament E. Cell-free DNA screening for fetal aneuploidy as a clinical service. Clin Biochem. 2015;48(15):932-41.

12. Hall MP, Hill M, Zimmermann B, Sigurjonsson S, Westemeyer M, Saucier J, et al. Non-invasive prenatal detection of trisomy 13 using a single nucleotide polymorphism- and informatics-based approach. PLoS One. 2014;9:e966-77.

13. Ryan A, Hunkapiller N, Banjevic M, Vankayalapati N, Fong N, Jinnett KN et al. Validation of an Enhanced Version of a Single-Nucleotide Polymorphism-Based Noninvasive Prenatal Test for Detection of Fetal Aneuploidies. Fetal Diagn Ther. 2016;40(3):219-23. 
14. Rieneck K, Clausen FB, Dziegiel MH. Noninvasive Antenatal Determination of Fetal Blood Group Using Next-Generation Sequencing. Cold Spring Harb Perspect Med. 2015;6(1):a023093.

15. Ma D, Yuan Y, Luo C, Wang Y, Jiang T, Guo F et al. Noninvasive prenatal diagnosis of 21-Hydroxylase deficiency using target capture sequencing of maternal plasma DNA. Sci Rep. 2017;7(1):7427.

16. Amicucci P, Gennarelli M, Novelli G, Dallapiccola B. Prenatal diagnosis of myotonic dystrophy using fetal DNA obtained from maternal plasma. Clin Chem. 2000;46(2):301-2.

17. Li Y, Page-Christiaens GC, Gille JJ, Holzgreve W, Hahn S. Non-invasive prenatal detection of achondroplasia in size-fractionated cell-free DNA by MALDI-TOF MS assay. Prenat Diagn. 2007;27(1):11-7.

18. Gil MM, Galeva S, Jani J, Konstantinidou L, Akolekar R, Plana MN et al. Screening for trisomies by cfDNA testing of maternal blood in twin pregnancy: update of The Fetal Medicine Foundation results and meta-analysis. Ultrasound Obstet Gynecol. 2019;53(6):734-42.

19. Beulen L, Faas BHW, Feenstra I, van Vugt JMG, Bekker MN. Clinical utility of non-invasive prenatal testing in pregnancies with ultrasound anomalies. Ultrasound Obstet Gynecol. 2017;49(6):721-8.

20. Hui L. Noninvasive prenatal testing for aneuploidy using cell-free DNA - New implications for maternal health. Obstet Med. 201;9(4):148-52.

21. Scott FP, Menezes M, Palma-Dias R, Nisbet D, Schluter P, da Silva Costa F et al. Factors affecting cell-free DNA fetal fraction and the consequences for test accuracy. J Matern Fetal Neonatal Med. 2018;31(14):1865-72.

22. Benn P, Plon SE, Bianchi DW. Current Controversies in Prenatal Diagnosis 2: NIPT results suggesting maternal cancer should always be disclosed. Prenat Diagn. 2019;39(5):339-43.

23. Wang Y, Chen Y, Tian F, Zhang J, Song Z, Wu Y, Han $X$ et al. Maternal mosaicism is a significant contributor to discordant sex chromosomal aneuploidies associated with noninvasive prenatal testing. Clin Chem. 2014;60(1):251-9.

24. Hui L, Bethune M, Weeks A, Kelley J, Hayes L. Repeated failed non-invasive prenatal testing owing to low cell-free fetal DNA fraction and increased variance in a woman with severe autoimmune disease. Ultrasound Obstet Gynecol. 2014;44(2):242-3.

25. Grömminger S, Erkan S, Schöck U. The influence of low molecular weight heparin medication on plasma DNA in pregnant women. Prenat Diagn. 2015;35:1155-7.

26. Uldbjerg N. No-call non-invasive prenatal testing gives important information. Int $\mathbf{J}$ Obstet Gynaecol. 2018;125(7):856.

27. Benn P, Valenti E, Shah S, Martin K, Demko Z. Factors Associated With Informative Redraw After an Initial No Result in Noninvasive Prenatal Testing. Obstet Gynecol. 2018;132(2):428-35.

28. Norton ME, Biggio JR, Kuller JA, Blackwell SC. The role of ultrasound in women who undergo cell-free DNA screening. Am J Obstet Gynecol. 2017;216(3):B2-7.

Cite this article as: Mangla M. Non-invasive prenatal testing: what an obstetrician needs to know. Int J Reprod Contracept Obstet Gynecol 2020;9:5200-4. 